\title{
Forced Expiratory Volume in 0.05 Second
}

National Cancer Institute

\section{Source}

National Cancer Institute. Forced Expiratory Volume in 0.05 Second. NCI Thesaurus.

Code C139246.

The volume of air that can be forcibly exhaled during the first 0.05 second following maximal inhalation. 